Vol. 3, No. 1, 2016

UDC 658.12

O. S. Vysochan

Doctor of Economic Sciences, Associate Professor,

I. V. Lutsiuk

Assistant Lecturer,

Lviv Polytechnic National University

\title{
INTENSIFICATION OF INTERNAL CONTROL OVER QUALITY COSTS AS A MEANS OF IMPROVING PRODUCT COMPETITIVENESS
}

\begin{abstract}
The article explores the application of the active control over quality costs that gives an opportunity not only to identify existing deficiencies and deviations, but also to optimize the structure and amount of quality costs, and to forecast future changes. The extension and modification of the tasks of the control over quality costs at the transition from passive to active forms is considered. The specific features of the active control system that distinguish it from the traditional one are identified. These include the control functions, the controller's responsibility, and the controller's qualification. The model of control cycle with using the active control system is developed. It includes the following stages: preparation, implementation, subcritical stage of the controlled object modification, and an inertial stage. The essence of the control stages and the possible states of a controlled object are characterized.

Key words: internal control, quality costs, quality management, accounting information, control model.
\end{abstract}

\section{Problem statement}

Internal control is an important component of the quality management system. Its effective organization gives an opportunity to assess the actual state and to identify the deficiencies in the enterprise activities in the field of quality, to establish the reasons for deviations, and to implement measures for their elimination and prevention.

The efficient quality management system requires to depart from a pattern procedures and to enhance the intellectualization of control over quality costs. That is manifested not only in fixing the identified problems, but in providing the preconditions for their prevention in the future; not just in achieving a positive result after the implementation of all control procedures, but (and this is the main thing) in its optimization.

\section{Analysis of recent research and publications}

The issues of internal control have been explored in the research works of O. Arvinge [1],
S. Briciua, A. Danescu, C. Danescu and M. Prozana [3], F. Conijn and H. Rouwelaar [4], N. Macintosh and P. Quattrone [10], K. Rae and N. Subramaniam [13] and others.

An important contribution to the investigation of the issues related to the control over quality costs was made by such scholars as S. Brad, M. Fulea, B. Mocan [2], A. Feigenbaum [6], Z. Irani and P. Love [8], R. Luther and I. Sartawi [9], H. Meier [11], P. Miguel and C. Pontel [12], S.-S. Shang and J.-X. You [14] and others.

In current competitive market conditions, not only the accuracy and reliability of economic information regarding the quality costs but also development of means for optimization of their content, structure and value are important and relevant.

As F. Conijn and H. Rouwelaar point out, "controllers must understand their changing role due to developing trends in business and social development. The controller must adapt adequately and in a timely fashion to these developments in order to keep adding value to the business and thus assuring or strengthening their position in the organization" [4].

Research objective is to develop suggestions for improving internal control over quality costs in order to increase the enterprise product competitiveness.

\section{Research material}

Development of quality management caused a necessity of transfer from the "passive" (conventional) control system, in which the cycle is completed at the stage of forming conclusions and recommendations, to the "active" (novel) where control continues until the object achieves its optimal parameters.

In the judgment of $\mathrm{O}$. Arwinge, "internal control seems to be an all-encompassing process. 


\section{O. S. Vysochan, I. V. Lutsiuk}

The wider approaches to internal control have expanded its boundaries significantly, far beyond the financial reports and the duties of the accountant. Financial reporting quality objectives have been supplemented with other internal control objectives which are related to compliance, efficiency and effectiveness" [1, p. 147].

The most representative presentations of the internal control are shaped in: COSO Model published on The Committee of Sponsoring Organizations of the Treadway Commission's initiative, COCO Model published on The Canadian Institute of Chartered Accountants' initiative, Turnbull Model published by the Institute of Chartered Accountants in England and Wales - ICAEW, the AMF Model published on L'Autorité des Marchés Financiers from France' initiative, CobiT Model published by IT Governance Committee (ITGC), Information Systems Audit and Control Association (ISACA), Basel Model enacted by Basel Committee on Banking Supervision. Some specific models are also ISA 315 Model (International Auditing and Assurance Standards Board - The Chamber of Financial Auditors of Romania, 2013), SAC Model published by the Internal Auditors Research Foundation (IIARF), the internal control model specific for the administration of state revenues in Romania (S.Briciu et all, 2011), etc. [3].

According to "Internal Control - Integrated Framework", one of the most widely practised models of internal control released by the Committee of Sponsoring Organizations of the Treadway Commission (COSO) [5], internal control consists of five integrated components: control environment, risk assessment, control activities, information and communication, and monitoring activities.

As J. A. Hall points out [7], the internal control shield is composed of three levels of control: preventive controls, detective controls, and corrective controls. This is the PreventiveDetective-Corrective (PDC) control model. Preventive controls are passive techniques designed to reduce the frequency of occurrence of undesirable events. Detective controls are devices, techniques, and procedures designed to identify and expose undesirable events. Corrective controls are actions taken to reverse the effects of errors detected in the previous step.

In applying the conventional control, when the function of the controller is solely detecting the deviations, the submission of recommendations for their elimination, and the punishment of those responsible, the controller seeks to minimize his/her own impact on the further development of the controlled object avoiding responsibility and reducing the risk of forming wrong judgments. In this case, the controller quite often intentionally or unintentionally overlooks the information, which is essential for the future development of the economic system, hiding behind the functional responsibilities or terms of the contract. Such a system of control, despite the maximum prevalence at Ukrainian enterprises, still does not meet the requirements of time and have to be replaced by a system of active control, in which the controller functions include among other things also the formulation of the recommendations to optimize the current position of the controlled object.

When the active control instruments are used along with the classical revision techniques (such as sample inventory, monitoring, control recount, review of the decisions implementation) the methods, which have a secondary role in "passive" control, such as economic analysis, logical interpretation, forecasting, modeling etc. come to the foreground. The controller should be ready to take responsibility not only for the creation and submission of wrong judgments about the state of the inspected object, but also for the state in which the inspected object will appear after implementing all the controller's recommendations.

Generally, the aim of internal control is to guarantee efficient operational activities results, reliability of financial reports, and adherence to related rules and regulations [15].

The primary tasks of a controller in accordance with active control concept are changing (Table 1).

The application of the (novel) control system in the accounting of quality costs expands the control tasks and considerably modifies them. In spite of this, the controller is not exempted from routine procedures inherent in traditional control.

In the coordinate system "the controller - the interested person", each of them receives additional benefits from the application of active control methods. Such gains for the controllers are additional financial bonuses; the opportunity to realize their own mental capacity; intellectual development not only through the gradual gaining of greater experience, but also due to intensive generation of innovative ideas. In return, the company gets additional economic, technical, organizational, and other benefits; effective redistribution of functional responsibilities and 
accountability between the managers and the controller; the opportunity to operate quality and valuable information on specific economic processes and events. By using methods of active control, a business entity gets not only extra benefits but also new knowledge that reduces the level of uncertainty concerning a particular problem.

\section{Table 1}

\section{Transformation of the quality costs control tasks when transferring from "passive" (conventional) to "active" (novel) control system*}

\begin{tabular}{|l|l|}
\hline Tasks of "passive" control & \multicolumn{1}{|c|}{ Tasks of "active" control } \\
\hline $\begin{array}{l}\text { 1. The determination of } \\
\text { the reliability of the infor- } \\
\text { mation about the amount } \\
\text { of quality costs }\end{array}$ & $\begin{array}{l}\text { 1. The assessment of the } \\
\text { economic feasibility of the } \\
\text { quality costs }\end{array}$ \\
\hline $\begin{array}{l}\text { 2. The establishment of } \\
\text { the completeness and } \\
\text { timeliness of reporting } \\
\text { information about the } \\
\text { quality costs in primary, } \\
\text { consolidated documents } \\
\text { and ledgers }\end{array}$ & $\begin{array}{l}\text { 2. The regulation and redi- } \\
\text { rection of information flows } \\
\text { regarding the quality costs in } \\
\text { order to maximize the } \\
\text { completeness and reliability } \\
\text { of the generated data and to } \\
\text { minimize information } \\
\text { pressure on managers at } \\
\text { various levels }\end{array}$ \\
\hline $\begin{array}{l}\text { 3. The establishment of } \\
\text { correct accounting of } \\
\text { quality costs in accordan- } \\
\text { ce with applicable law and } \\
\text { approved accounting } \\
\text { policy }\end{array}$ & $\begin{array}{l}\text { 3. The adjustment of the } \\
\text { methodology of quality cost } \\
\text { accounting within the legal } \\
\text { framework with due conside- } \\
\text { ration of the trends in the } \\
\text { decision-makers' information } \\
\text { needs }\end{array}$ \\
\hline $\begin{array}{l}\text { 4. The determination of } \\
\text { the reliability of the } \\
\text { reflection of the quality } \\
\text { costs in financial and } \\
\text { management reporting of } \\
\text { an enterprise }\end{array}$ & $\begin{array}{l}\text { 4. The redistribution and } \\
\text { optimization of the functional } \\
\text { duties of the enterprise } \\
\text { structural divisions in order to } \\
\text { maximize the effective for- } \\
\text { mation and timely submis- } \\
\text { sion of reporting forms to } \\
\text { interested parties }\end{array}$ \\
\hline
\end{tabular}

* Authors' development

The system of active (novel) control has a number of features, which distinguish it from traditional control systems.

In addition to traditional control functions, which include identifying of deviations and making recommendations for their elimination, active control performs optimization of the current position of the controlled object and makes forecasting of the future opportunities and threats for the achievement of optimal parameters.
In this connection, the controller's responsibility increases because of the necessity of postcontrol support for the modification of the controlled object until it reaches the desired parameters.

The requirements to qualification of the controller also increase. The qualification should be high with a steady trend towards improvement (professional development, participation in scientific workshops, professional round-tables, personal involvement in field checks etc.). Additional necessary characteristics are ability to think creatively, to provide unconventional solutions, readiness to take additional responsibility, powerful logical and analytical skills, continuing selfimprovement etc.

All the above considerations lead us to the need to present the control cycle model with elements of the active (novel) control system (Fig. 1).

The control cycle in Fig. 1 is divided into three main stages. During the preparation stage, primary accumulation of resources necessary for the effective implementation of control procedures occurs. It includes approval of the control plan, goals setting, determination of specific techniques and their implementers etc. At the implementation phase, all the necessary procedures to achieve the objectives defined in the previous stage are carried out. In case of applying passive control here the inspector's work is finished and he returned to preparing the following control procedures. After the control itself is completed, there begins the stage of modification of the controlled object, i.e. bringing it into the line with certain predetermined and, if necessary, adjusted reference parameters. This stage is divided into two sub-steps: subcritical and inertial. During the first of these, changes that occur with the controlled object can be reversed using additional resources (it can be initiated by management if passive control is used, or management and controllers if active control is used). During the inertial stage, the object is found in the resultant state and the changes that occurred are already irreversible.

Identification of the inertial phase is primarily connected with the existence of the factors of the environment that is external to the system "controller - management", the factors that cannot be affected by either management or the controller at all or their impact is minimal. The nature of these forces can be either global (applies to all entities in the country or industry), among them being the change of legislation, the 


\section{O. S. Vysochan, I. V. Lutsiuk}

deterioration of market conditions etc. or local (refers to a specific entity), for example, contractors' failure to comply with contractual obligations, change of certain officials etc. At the stage of inertial modification of the controlled object, to avoid the effect of these forces is impossible though when using the active (novel) control there emerges the need in their forecasting, however, the controller has, on the one hand, full responsibility for the formation of wrong conclusions following the results of the inspection and, on the other hand, he/she bears partial responsibility for the absence of the positive result.

Characteristics of the control cycle when using active control system in the area of quality costs are shown in Table 2.

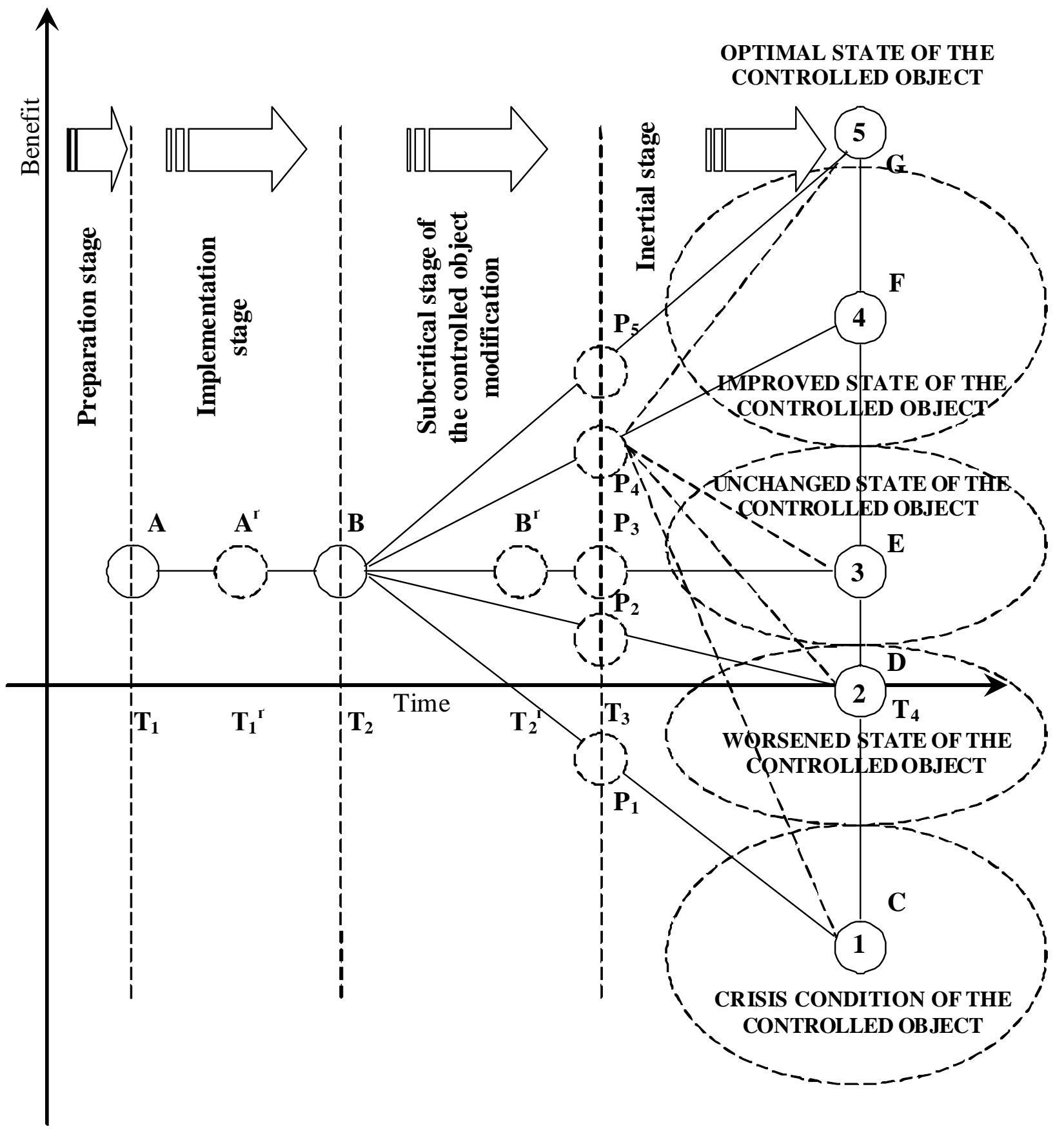

Fig. 1. The model of control cycle with elements of the active control system* 
Table 2

Characteristics of the stages of internal control over quality costs*

\begin{tabular}{|c|l|}
\hline Stage & \multicolumn{1}{|c|}{ Characteristics } \\
\hline Preparation stage & $\begin{array}{l}\text { Establishment of the goals and } \\
\text { objectives of internal control } \\
\text { over the quality costs, control } \\
\text { planning, preparation of } \\
\text { control program and selection } \\
\text { of control procedures }\end{array}$ \\
\hline Implementation stage & $\begin{array}{l}\text { Direct implementation of the } \\
\text { control procedures in order to } \\
\text { establish the lawfulness and } \\
\text { the accuracy of identification } \\
\text { and the accounting reflection } \\
\text { of the quality costs in terms of } \\
\text { responsibility centres and } \\
\text { assessment of the of quality } \\
\text { cost management effectiveness }\end{array}$ \\
\hline $\begin{array}{c}\text { Subcritical stage of } \\
\text { the controlled object } \\
\text { modification }\end{array}$ & $\begin{array}{l}\text { Adjustment of the existing } \\
\text { management system parame- } \\
\text { ters by the control instruments } \\
\text { aimed at optimization of quality } \\
\text { costs }\end{array}$ \\
\hline $\begin{array}{l}\text { Minimization of negative } \\
\text { consequences of external and } \\
\text { internal influence on the state } \\
\text { of the quality management } \\
\text { system and forecasting its } \\
\text { development in the medium } \\
\text { and long term perspective }\end{array}$ \\
\hline
\end{tabular}

* Authors' development

This leads us to the idea of existing some critical points (P1-P5) in each segment, when there is still the possibility of changing the state of the quality costs. Consequently, it is possible to change the resulting positions on the segment of enterprise usefulness (from point $\mathrm{C}$ to point $\mathrm{G}$ ) in one or another direction. After passing through these points in time, to overcome the inertia of an object provided by the control means is impossible and the latter turns out to be in one of the aforementioned states. The initiator of changes in the motion path of the controlled object can be the company's management, company's particular divisions (including accounting) and the controllers themselves.

Obviously, the location of points (P1-P5) directly depends on the ratio of the subcritical and inertial phase duration. The subcritical stage is shorter in the following cases:

- the obtained control results are provided to the users without delay and within a specified time period;
- the management wants and is qualified enough to be able without the involvement of additional experts and unnecessary intermediate procedures to process the information and develop necessary decisions;

- management response to the information obtained after the control procedures is maximally quick and is communicated to the executives in the shortest possible time.

The inertial stage is shorter in the following cases:

- there is no significant influence of extraneous factors on the modification of the controlled object, which would impede its change;

- parameters of the modified object are insignificantly different from the original and do not require a significant amount of human, financial and other resources.

At the end of the trajectory of motion, the controlled object for a certain time (T4) may be in one of five possible positions:

1 - unqualified conduction of the control process has led to the condition when the company received the minimum possible benefits and the correction of which will cost significant additional resources;

2 - the controller's recommendations brought negative result due to the errors in implementation of control procedures or wrong controller's judgments;

3 - control has not brought the desired result: the errors were not identified or the controller's recommendations were not taken into account by the company's managers;

4 - during the inspection there was revealed a number of drawbacks, the removal of which brought some benefit to the company;

5 - application of active control techniques allowed not only to detect and correct mistakes, but also to optimize the state of the controlled object, which leads to maximizing the company's usefulness.

Let us characterize each of the five stages of quality costs presented in Fig. 1:

- crisis - the most dangerous situation, when due to incompetence or criminal intentions the controller makes recommendations following the results of the audit, the implementation of which not only leads to the absence of any positive effect towards improving the state of affairs on a separate piece of work but also threatens the company's business activities; 
- worsened - inspection of quality costs has brought a negative result, which usually manifests itself as excessive spending of resources (financial, human etc.) in comparison with the obtained effect. This may be a result of either low qualification of the controller, his formal attitude to work, lack of basic conditions for effective inspection etc. or unwillingness of the company management to listen to the controller's recommendations and to take measures to improve the current state of affairs. Motivation can be very diverse: from the expression of distrust in the control results and lack of resources for improving the situation to the criminal actions aimed at the pursuit of private interests by governing bodies or individual responsible persons;

- unchanged - control procedures did not bring any significant positive effect. The case is typical of many large enterprises in carrying out the statutory audit to confirm reporting when its realization is dictated more by the requirements of the current legislation than the real needs of a business entity. Quite often, neither the controllers nor the company's management are interested in getting real results, therefore the audit becomes a formal procedure with a sample set of standard actions and a known outcome. Obviously, we are discussing the comparatively constant state of the controlled object, when either positive or negative changes are insignificant. Pay attention to the fact that the steady-state condition of the controlled object after carrying out the relevant procedures does not mean the absence of errors in the implementation and registration of certain business operations; on the contrary, this may often indicate deficiencies in the organization of the control system itself;

- improved - the costs of conducting control measures are less than the benefits of their results. The benefits may be demonstrated in following: the avoidance or minimization of penalties; establishment or improvement of functional relations between the various elements of the enterprise management system; identification of gaps in the existing accounting policy in some enterprise areas etc.;

- optimal - a state that is achieved only when applying the active control system, based on which the controlled object maximally approaches the "standard" formed at the stage of preparing control procedures.

The states of the quality costs after completion of the active control cycle are characterized in Table 3.
Table 3

The possible quality costs states after application of active control and their characteristics*

\begin{tabular}{|c|c|}
\hline $\begin{array}{c}\text { State of the } \\
\text { controlled object }\end{array}$ & Characteristics \\
\hline Crisis & $\begin{array}{l}\text { Incompetent controller's recommen- } \\
\text { dations regarding the quality costs } \\
\text { can lead to reduced product quality, } \\
\text { and, as a consequence, to the threat to } \\
\text { the consumers' life and health, legal } \\
\text { claims, damage the enterprise repu- } \\
\text { tation etc. }\end{array}$ \\
\hline Worsened & $\begin{array}{l}\text { The costs of implementing control } \\
\text { procedures exceed the useful effect. } \\
\text { The amount and structure of quality } \\
\text { costs can be both unchanged so } \\
\text { worsened regarding their condition } \\
\text { before control }\end{array}$ \\
\hline Unchanged & $\begin{array}{l}\text { The control over quality costs is not } \\
\text { given due attention, controller only } \\
\text { checks formal compliance of costs } \\
\text { documentation with their reflection } \\
\text { in reports. }\end{array}$ \\
\hline Improved & $\begin{array}{l}\text { There are fixed some shortcomings in } \\
\text { the organization of the quality costs } \\
\text { accounting, improved functional } \\
\text { relationships between the elements } \\
\text { of the quality management system }\end{array}$ \\
\hline Optimal & $\begin{array}{l}\text { The minimal costs of quality asses- } \\
\text { sment and control required to ensure } \\
\text { an adequate level of product quality. } \\
\text { In this case, the external and internal } \\
\text { losses caused by inadequate product } \\
\text { quality are close to zero. }\end{array}$ \\
\hline
\end{tabular}

* Authors' development

Consequently, the final aim of the active control is the achievement of the optimal state of the controlled object, i.e. the state in which the quality costs bring the maximum benefit to the business entity. The benefit can be manifested in improving the value of various indicators of economic (profit increase, cost reduction etc.), technical (increase of equipment performance, reduction of the manufacturing defects etc.), and organizational character (structuring of information flows between different enterprise departments, redistributing functional responsibilities within a specific service).

\section{Conclusions}

The implementation of active control system at the enterprise as a whole and in the area of the quality costs accounting should be the basis of forming the information base for rational mana- 
gement decisions making and the tool to guide managers in the direction of the only appropriate decision. The controller becomes not only the specific data producer, but also manager assistant in understanding and working in the newly created information flows, sharing with him both the reward for success and responsibility for failure. Therefore, the controller needs not only to state the formal existence of a problem and to briefly outline the direction of its solution, but also to take direct part in the solution of this problem and propose well-founded optimal ways of its overcoming using minimal resources with the maximum effect, to generate recommendations to prevent it in the future and to implement subsequent control over the process of its solution.

\section{References}

1. Arwinge O. (2013) Internal Control. A Study of Concept and Themes. Springer-Verlag Berlin Heidelberg.

2. Brad S., Fulea M. \& Mocan B. (2006) Expert System for Quality Cost Planning, Monitoring and Control. 2006 IEEE International Conference on Automation, Quality and Testing, Robotics, pp. 53-58.

3. Briciua S., Danescu A. C., Danescu T., Prozana M. (2014) A Comparative Study of Well-Established Internal Control Models. Procedia Economics and Finance 15, pp. 1015-1020.

4. Conijn F. \& Rouwelaar H. (2012) How Will the Control Function Look in 2020? Management accounting, pp. 243-250.

5. COSO, Internal Control - Integrated Framework (2013). Available at: http://www.coso.org/documents/ 990025p_executive_summary_final_may20_e.pdf
6. Feigenbaum A. (1991) Total Quality Control, 3rd ed. New York: McGraw-Hill.

7. Hall J. A. (2016) Accounting Information Systems, Ninth Edition. Cengage Learning.

8. Love P. \& Irani Z. (2003) A Project Management Quality Cost Information System for the Construction Industry. Information \& Management, Vol. 40, Iss. 7, pp. 649-661.

9. Luther R. \& Sartawi I. (2011) Managerial Practices of Quality Costing: an Evidence-Based Framework. International Journal of Quality \& Reliability Management, Vol. 28 Iss: 7, pp. 758-772.

10. Macintosh N., Quattrone P. (2010) Management Accounting and Control Systems. An Organizational and Sociological Approach. UK: John Wiley and Sons Ltd.

11. Meier H. H. (1991) A Control Model for Assessing Quality Cost. American Journal of Business, Vol. 6 Iss: 1, pp. 40-44.

12. Miguel P. A. \& Pontel C. S. (2004) Assessing Quality Costs of External Failures (Warranty Claims). International Journal of Quality \& Reliability Management, Vol. 21 Iss: 3, pp. 309-318.

13. Rae K., \& Subramaniam, N. (2008). Quality of internal control procedures: Antecedents and moderating effect on organizational justice and employee fraud. Managerial Auditing Journal, 23(2), pp. 104-124.

14. Shang S.-S. \& You J.-X. (2009) Quality cost control model based on fuzzy neural network. Industrial Engineering and Engineering Management, 16th International Conference, pp. 1112-1116.

15. The Establishment of an Internal Control System. Special Reports. Available at: https://www.icdf.org.tw/ web_pub/20040517151210The\%20Establishment....pdf 
